\title{
PERANGKAT PEMBELAJARAN MODEL INKUIRI DIPADU ADVANCE ORGANIZER UNTUK MENINGKATKAN PENGUASAAN KONSEP DAN KEMAMPUAN PEMECAHAN MASALAH FISIKA SISWA
}

\section{LEARNING TOOLS IN INQUIRY MODELS WITH ADVANCE ORGANIZER TO IMPROVE UNDERSTANDING OF CONCEPT AND PROBLEMS SOLVING ABILITY OF STUDENTS IN PHYSISCS}

\author{
Mir'atun Nisyah $^{1 *}$, Gunawan Gunawan ${ }^{2}$, Ahmad Harjono², dan Mahesti Kusdiastuti ${ }^{1}$ \\ ${ }^{1}$ Program Studi Magister Pendidikan IPA, Universitas Mataram, Indonesia \\ ${ }^{2}$ Program Studi Pendidikan Fisika, Jurusan Pendidikan MIPA, FKIP, Universitas Mataram, Indonesia \\ *Email: miratunnissa45@gmail.com
}

Diterima: 27 Mei 2019. Disetujui: 29 Mei 2019. Dipublikasikan: 31 Juli 2019

\begin{abstract}
Abstrak: Penelitian ini menyajikan hasil validasi dan uji coba terbatas perangkat pembelajaran model inkuiri dipadu advance organizer untuk meningkatkan penguasaan konsep dan kemampuan pemecahan masalah fisika siswa. Prosedur pengembangan yang digunakan adalah model 4D yang terdiri dari tahap define (Pendefinisian), design (Perancangan), development (Pengembangan), dan disseminate (Penyebaran). Perangkat pembelajaran yang dikembangkan terdiri dari silabus, rencana pelaksanaan pembelajaran, media pembelajaran, dan instrumen tes penguasaan konsep dan kemampuan pemecahan masalah. Hasil validasi menunjukkan perangkat pembelajaran dalam kategori layak-sangat layak. Hasil uji coba terbatas menunjukkan bahwa respon siswa sebesar $79.95 \%$ dan guru sebesar $81.15 \%$ adalah praktis dan terbaca, sehingga dapat disimpulkan bahwa perangkat pembelajaran model inkuiri dipadu advance organizer layak, praktis dan terbaca dan dapat digunakan dalam pembelajaran fisika.
\end{abstract}

Kata Kunci: Advance Organizer, Kemampuan Pemecahan Masalah, Model Inkuiri, Penguasaan Konsep, Perangkat Pembelajaran

\begin{abstract}
This study presents the results of validation and limited trials of learning tools in inquiry model with advance organizer to improve concepts of understanding and problem solving ability of students. The development procedure used is 4D model which consists of define, design, development disseminate. Learning tools developed are syllabus, lesson plan, learning media, and understanding of concept and problem solving instrument tests. The validation results show the learning tools in the feasible- very feasible. The results of limited trial show that students' responses of $79.95 \%$ and teachers of $81.15 \%$ are practical and legible. So it can be concluded that learning tools in inquiry with advance organizer are feasible, practical and legible and can be used in physics learning.
\end{abstract}

Keywords: Advance Organizer, Problem Solving Ability, Inquiry Model, Learning Tools, Understanding of Concept

\section{PENDAHULUAN}

Pendidikan merupakan cara untuk mempersiapkan dan mengembangkan kompetensi siswa sebagai generasi bangsa dalam mengimbangi setiap perkembangan tatanan kehidupan yang semakin kompleks di abad 21. Siswa perlu dibekali keterampilan yang dibutuhkan untuk menghadapi tantangan abad 21 diantaranya adalah bekerja sama, berkomunikasi, kreativitas, dan berpikir kritis serta keterampilan dalam menyelesaikan masalah [1,2]. Gagne [3] menyatakan individu yang memiliki kemampuan berpikir dan pemecahan masalah akan sukses dalam kehidupan pribadi dan masyarakat.

Sains merupakan salah satu bagian dari pendidikan yang dikaitkan dengan kualitas individu dan kecerdasan bangsa. Fisika merupakan salah satu cabang dari sains yang memfokuskan kajian pada materi, energi, dan hubungan antara keduanya [4,5]. Tujuan utama pembelajaran fisika adalah agar siswa dapat menjadi pemecah masalah yang baik [6].

Kemampuan pemecahan masalah adalah kapasitas proses kognitif seseorang untuk memahami dan menyelesaikan masalah [7]. Kemampuan pemecahan masalah fisika siswa terjadi dalam lima tahapan yaitu memfokuskan masalah, mendeskripsikan masalah dalam konsep fisika, merencanakan penyelesaian, melaksanakan rencana, dan mengevaluasi [8]. Pemecahan masalah membutuhkan kemampuan siswa untuk 
membangun hubungan antara pengetahuan baru dengan pengetahuan yang telah dimiliki.

Kemampuan dalam membangun hubungan antara pengetahuan baru dengan pengetahuan yang telah dimiliki merupakan salah satu indikator bahwa siswa mempunyai kemampuan pemecahan masalah yang baik. Kenyataannya, siswa tidak mampu untuk memenuhi indikator tersebut. Hal ini menyebabkan kemampuan pemecahan masalah siswa masih sangat rendah. Susiana et al [9] menemukan bahwa kemampuan pemecahan masalah fisika siswa Sekolah Menengah Atas (SMA) masih sangat rendah, hal ini ditunjukkan oleh hasil tes dari kelima tahap kemampuan pemecahan masalah dalam kategori rendah. Hasil studi literatur, observasi dan wawancara diperoleh bahwa kemampuan pemecahan masalah siswa yang rendah disebabkan oleh faktor-faktor diantaranya: implementasi model, media dan bahan ajar yang kurang memfasilitasi siswa berlatih memecahkan masalah selain itu penguasaan siswa terhadap konsep yang belum maksimal.

Inovasi perlu dilakukan sebagai upaya memaksimalkan penguasaan konsep dan kemampuan pemecahan masalah, Saputra et al [10] menyatakan implementasi pembelajaran memadukan dua model pembelajaran efektif membantu siswa mengembangkan kemampuan berpikir tingkat tinggi. Selain itu, penggunaan media pembelajaran tepat efektif meningkatkan pengguasaan konsep dan kemampuan pemecahan masalah [11]. Berdasarkan uraian ini, solusi yang ditawarkan peneliti untuk mengatasi masalah di atas adalah pengambangan perangkat pembelajaran model inkuiri dipadu advance organizer. Perangkat pembelajaran adalah perlengkapan yang berisi perencanaan yang digunakan sebagai pedoman dalam melaksanakan dan mencapai tujuan pembelajaran. Pembelajaran model inkuiri dipadu advance organizer adalah model yang dikembangkan berdasarkan teori kontrusktivis dan pembelajaran bermakna.

Model inkuiri merupakan salah satu model pembelajaran yang memberikan pengalaman siswa membangun pengetahuan melalui kegiatan inkuiri ilmiah untuk memecahkan masalah [12]. Beberapa penelitian terdahulu menunjukkan bahwa penerapan model inkuiri dapat meningkatkan kemampuan pemecahan masalah siswa [13, 14]. Aktivitas inkuiri membutuhkan keterampilan berpikir tingkat tinggi sehingga tidak semua siswa siap untuk melakukan hal itu secara langsung, sehingga diperlukan sebuah strategi untuk mempersiapkan siswa untuk melakukan aktivitas tersebut. Salah satu strategi yang bisa digunakan adalah mengintegrasikan fitur-fitur pembelajaran bermakna ke dalam model inkuiri.
Pembelajaran bermakna terjadi jika sudah memiliki pengetahuan atau pengalaman dengan materi baru yang akan dipelajari [15]. Salah satu model yang menerapkan fitur-fitur pembelajaran bermakna adalah model advance organizer. Model advance organizer adalah sebuah model pengajaran kognitif yang digunakan untuk mempromosikan pembelajaran dan penyimpanan informasi baru [16]. Model pembelajaran ini terdiri dari tiga fase yaitu presentasi advance organizer, presentasi materi tugas, dan penguatan struktur kognitif [17].

Advance organizer adalah informasi yang disajikan berupa konsep-konsep dan hubungan antar konsep sebelum pembelajaran yang digunakan untuk mengintegrasikan pengetahuan baru dengan pengetahuan yang sudah ada dalam struktur kognitif siswa [18]. Struktur kognitif seseorang adalah faktor terpenting yang memerintahkan apakah materi baru akan bermakna dan seberapa bagus dapat diperoleh dan dipertahankan [15]. Berdasarkan uraian ini, presentasi advance organizer dapat menjadi scaffolding yaitu menyajikan kerangka konsep dan kerja dalam kegiatan inkuiri [19].

Penguatan struktur kognitif dapat dilakukan dengan prinsip rekonsiliasi integratif yaitu pengorganisasian konsep-konsep agar yang dapat membantu penerimaan dan penyimpanan konsep dalam memori struktur kognitif siswa [20]. Ketika penerimaan dan penyimpanan konsep dalam struktur kognitif siswa terjadi dengan baik, maka akan berpengaruh terhadap pemahaman dan penguasaan konsep siswa. Penelitian terdahulu menunjukkan bahwa penggunaan advance organizer dalam pembelajaran memberikan pengaruh positif terhadap hasil belajar [21] dan kemampuan pemecahan masalah fisika siswa [22].

Berdasarkan uraian di atas dapat disimpulkan bahwa model advance organizer dapat diintegrasikan dengan model inkuiri. Sehingga perangkat pembelajaran yang akan dikembangkan dalam penelitian ini adalah perangkat pembelajaran model inkuiri dipadu advance organizer untuk meningkatkan penguasaan konsep dan kemampuan pemecahan masalah fisika siswa. Tujuan penelitian ini adalah mengetahui kelayakan dan kepraktisan perangkat pembelajaran yang dikembangkan.

\section{METODE PENELITIAN}

Penelitian ini merupakan penelitian pengembangan dengan model pengembangan mengikuti tahap pengembangan $4-\mathrm{D}$, yang terdiri dari empat tahap yaitu: tahap pendefinisian (Define), tahap perancangan (Design), tahap pengembangan (Develop), dan tahap penyebaran (Disseminate) [23]. Pada penelitian ini hanya dibatasi sampai pada tahap uji coba terbatas. Perangkat pembelajaran yang dikembangkan yaitu silabus, Rencana Pelaksanaan Pembelajaran (RPP), 
Lembar Kerja Siswa (LKPD), Graphic Organizer (GOs) dalam bentuk peta konsep, Materi ajar, intrumen tes penguasaan konsep dan pemecahan masalah.

Pengembangan perangkat pembelajaran dimulai dengan pengumpulan informasi terkait masalah-masalah yang muncul dalam pembelajaran, sehingga dapat dirumuskan solusi untuk mengatasinya. Tahap selanjutnya adalah untuk menyusun prototipe yang dikembangkan seperti penyusunan standar tes, pemilihan media, pemilihan format, dan melakukan rancangan awal perangkat pembelajaran. Hasil rancangan awal perangkat pembelajaran dilakukan uji validitas ahli dan uji kepraktisan pada guru fisika dan siswa di salah satu SMAN di Mataram.

Data validasi dan kepraktisan diperolah menggunakan angket dengan interval penskoran 1-
5, kemudian dihitung menggunakan rumus skor rata-rata. Hasil perhitungan validasi diintepretasi dengan kriteria: $4,2 \geq \mathrm{SV} \leq 5,0=$ sangat layak; $3,4 \geq \mathrm{SV} \leq 4,2=$ layak; $2,6 \geq \mathrm{SV} \leq 3,4=$ cukup layak; $1,8 \geq \mathrm{SV} \leq 2,6=$ kurang layak; dan $1,0 \geq$ SV $\leq 1,8=$ tidak layak [24]. Kriteria penilaian kepraktisan dan keterbacaan perangkat meliputi; 75 - $100 \%=$ praktis dan terbaca; $50-74 \%=$ cukup praktis dan dapat terbaca,; $25-49 \%=$ tidak praktis dan tidak terbaca [25].

\section{HASIL DAN PEMBAHASAN}

Karakteristik Perangkat Pembelajaran Model Inkuiri dipadu Advance Organizer

Spesifikasi dan desain awal perangkat pembelajaran yang dikembangkan dapat dilihat pada Tabel 1 .

Tabel 1. Spesifikasi Perangkat Pembelajaran Model Inkuiri dipadu Advance Organizer

\begin{tabular}{cll}
\hline No & Komponen & Uraian Isi \\
\hline 1. & Silabus & Tabel perencanaan pembelajaran yang memuat tentang kompetensi \\
& & dasar mata pelajaran, indikator pencapaian kompetensi, materi, \\
& kegiatan pembelajaran, teknik penilaian, alokasi waktu \\
& pembelajaran, dan sumber belajar
\end{tabular}

2. RPP

3. GOs

4. LKPD

5. Materi ajar

6. Instrumen Tes Penguasaan Konsep

7. Instrumen Tes Kemampuan Pemecahan Masalah
Rumusan tujuan pembelajaran menunjukkan kecakapan abad 21 dan IPK dikembangkan untuk mencapai KD.

Materi dikembangkan sesuai dengan karakteristik KD dan struktur penyajian sesuai prosedur (ada fakta, konsep, prosedural dan metakognitif).

Pemilihan metode dan media pembelajaran yang digunakan sesuai dan dapat mendukung peningkatan penguasaan konsep dan kemampuan pemecahan masalah.

Langkah pembelajaran sesuai dengan tujuan pembelajaran, model inkuiri dipadu advance organizer dan alokasi waktu.

Peta konsep dari materi pembelajaran

Kegiatan dalam LKPD dirancang sesuai dengan fase-fase model pembelajaran inkuiri dipadu advance organizer dan tahapan pemecahan masalah yang meliputi memfokuskan masalah, mendeskripsikan masalah dalam konsep fisika, merencanakan penyelesaian masalah, melaksanakan rencana, dan mengevaluasi.

Materi disajikan sesuai tujuan pembelajaran.

Menyajikan contoh soal pemecahan masalah

Soal pilihan ganda yang mengacu pada kemampuan kognitif C1C6.

Soal uraian dengan kriteria penilaian sesuai tahapan pemecahan masalah yang dikembangkan oleh Heller et al [8]
Perangkat pembelajaran yang dikembangkan dalam penelitian ini memiliki ciri khas yaitu sintaks pembelajaran model inkuiri yang dipadu dengan fitur model pembelajaran bermakna yaitu advance organizer dan rekonsiliasi integratif. Menurut [10], perpaduan dua model efektif memaksimalkan 
pencapaian tujuan pembelajaran dan melatih kemampuan berpikir tingkat tinggi siswa. Selain itu, GOs, LKPD dan materi ajar disusun untuk memfasilitasi siswa secara aktif dan mandiri selama pembelajaran. Penelitian oleh [13] menemukan kombinasi media dan model pembelajaran yang sesuai dapat memberikan pengaruh positif terhadap penguasaan konsep dan kemampuan pemecahan masalah.

\section{Hasil Validasi Perangkat}

Prototipe perangkat pembelajaran divalidasi oleh tiga ahli pendidikan fisika untuk mengetahui tingkat kelayakan perangkat pembelajaran yang dikembangkan. Hasil validasi perangkat pembelajaran dapat dilihat pada Tabel 2 . Berdasarkan hasil validasi terlihat bahwa rata-rata perolehan skor setiap komponen perangkat pembelajaran masuk dalam kategori layak kecuali silabus dalam kategori sangat layak. Hasil ini sesuai dengan penelitian [13], pengembangan perangkat pembelajaran fisika berkategori layak dapat digunakan dalam penelitian sesuai dengan saran dari ahli.

Tabel 2. Hasil validasi perangkat pembelajaran.

\begin{tabular}{llccccc}
\hline \multirow{2}{*}{ No } & Perangkat & \multicolumn{3}{c}{ Validator } & \multirow{2}{*}{ Rata-rata } & Kategori \\
\cline { 3 - 5 } & & 1 & 2 & 3 & & Sangat Layak \\
\hline 1 & Silabus & 4,30 & 4,30 & 4,40 & 4,33 & Layak \\
2 & RPP & 4,19 & 4,20 & 3,90 & 4,10 & Layak \\
3 & LKPD & 4,00 & 3,90 & 4,00 & 3,97 & Layak \\
4 & GOs & 4,00 & 4,10 & 3,90 & 4,00 & Layak \\
5 & Materi Ajar & 3,95 & 4,10 & 4,00 & 4,02 & Layak \\
6 & Instrumen Soal & 4,00 & 4,00 & 4,10 & 4,03 & Layak \\
7 & Penguasaan Konsep & & & & & \\
& Instrumen Soal & 4,00 & 4,00 & 4,00 & & \\
\end{tabular}

Perangkat pembelajaran yang divalidasi telah mengalami revisi pada beberapa aspek seperti pada aspek tulisan yaitu konsistensi penulisan dan penggunaan kalimat yang operasional, aspek tampilan yaitu penyesuaian penggunaan gambar dalam LKPD dengan konsep yang dipelajari dan penyesuaian kegiatan LKPD dengan sintak model pembelajaran yang digunakan, aspek konten dari silabus dan RPP serta instrumen soal penguasaan konsep dan kemampuan pemecahan masalah yaitu penyesuaian penyajian soal dan indikator pencapaian kompetensi dengan soal. Perangkat pembelajaran yang telah dinyatakan layak oleh ahli selanjutnya diujicobakan dalam skala terbatas.

\section{Hasil Uji Coba Terbatas}

Uji coba terbatas dilakukan untuk mengetahui kepraktisan dan keterbacaan perangkat pembelajaran yang dikembangkan. Uji ini dilakukan oleh guru dan siswa disebabkan karena keduanya merupakan praktisi atau pengguna dari perangkat yang telah dibuat. Hasil uji kepraktisan perangkat pembelajaran terhadap siswa dan guru disajikan pada Gambar 1. 


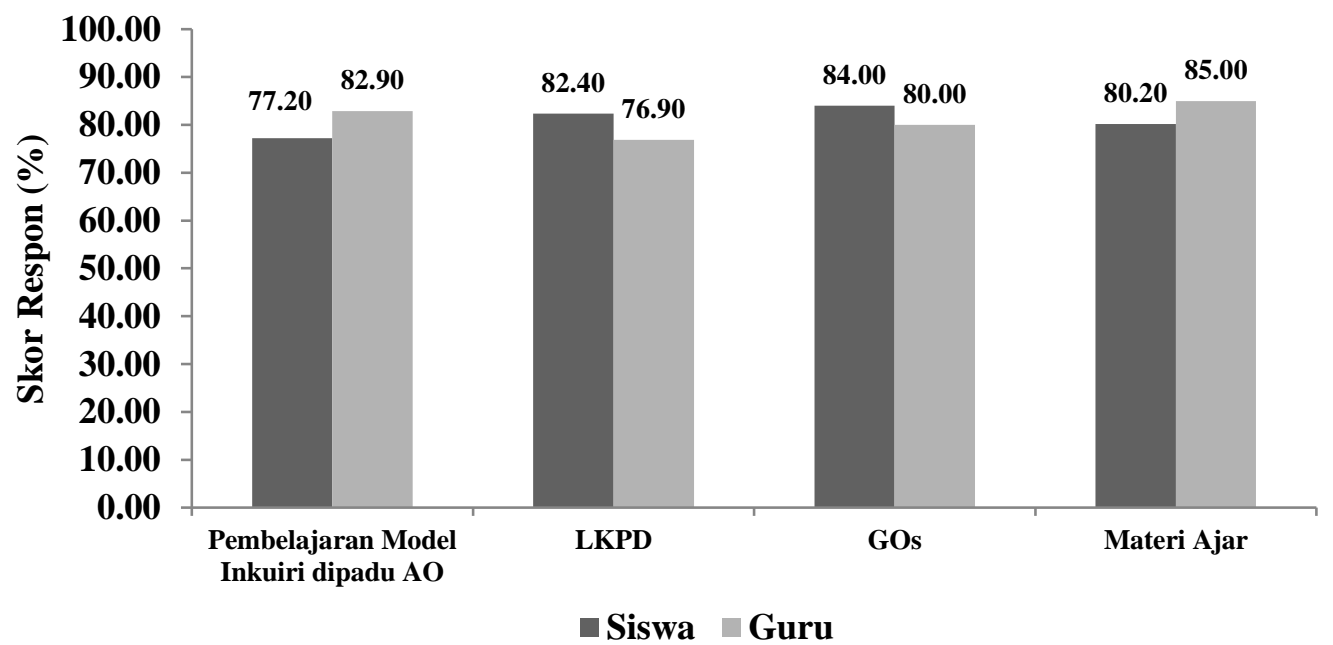

Gambar 1. Respon Siswa dan Guru terhadap Perangkat Pembelajaran Inkuiri dipadu AO

Gambar 1 menunjukkan bahwa respon siswa dan guru terhadap perangkat pembelajaran berkisar pada $76.00 \%-85.00 \%$ dalam kriteria praktis dan terbaca. Uji coba terbatas dilakukan untuk mengetahui tingkat keterbacaan perangkat pembelajaran oleh pengguna yaitu guru dan peserta didik. Hasil uji coba terbatas terhadap peserta didik diperoleh bahwa LKPD, GOs, dan materi ajar berkategori sangat baik. Sedangkan uji coba terbatas terhadap guru diperoleh bahwa RPP dan materi ajar berkategori sangat baik sedangkan LKPD dan GOs, berkategori baik. Uji coba RPP dan LKPD terkait dengan kejelasan langkah kegiatan, alokasi waktu, kesesuaian indikator dan tujuan dengan kompetensi dasar, kejelasan penggunaan bahasa dan tampilan. Sedangkan uji coba GOs dan materi ajar meliputi bentuk tampilan serta kejelasan konsep dan bahasa.

Hasil uji coba terbatas sesuai dengan [26] yang menyatakan uji coba terbatas dilakukan dengan uji keterbacaan perangkat pembelajaran oleh guru dan peserta didik berkategori baik dan sangat baik. Dengan demikian, dapat disimpulkan bahwa kalimat-kalimat dan langkah kegiatan dalam LKPD dan RPP mampu dipahami guru dan peserta didik serta dapat diterapkan dalam pembelajaran dengan skala yang lebih luas. Selain itu, [13] menyatakan bahwa tingkat keterbacaan perangkat pembelajaran yang tinggi dapat meningkatkan efisiensi dan efektivitas pembelajaran.

Hasil pengembangan yang berkualitas diperlukan partisipasi penggunaan untuk menyempurnakan produk [25]. Dalam uji coba terbatas saran dan kesulitan yang dialami siswa dan guru digunakan sebagai dasar untuk menyempurnakan produk sebelum digunakan dalam uji coba luas. Saran dari siswa dan guru diantaranya penyederhanaan penggunaan kata agar lebih mudah dimengerti, perbaikan gambar pada LKPD dan materi ajar. Saran dan masukan dijadikan sebagai bahan perbaikan perangkat yang dikembangkan sebelum dilakukan uji coba luas untuk mengetahui efektivitas pembelajaran menggunakan perangkat yang dikembangkan.

\section{KESIMPULAN}

Berdasarkan uji validitas dan uji kepraktisan, maka dapat disimpulkan bahwa perangkat model inkuiri dipadu advance organizer yang telah dikembangkan layak dan praktis digunakan dalam pembelajaran fisika. Tahap uji coba luas dapat dilakukan untuk mengetahui efektivitas pembelajaran menggunakan perangkat model inkuiri dipadu advance organizer dalam meningkatkan penguasaan konsep dan kemampuan pemecahan masalah fisika siswa.

\section{UCAPAN TERIMAKASIH}

Tim peneliti mengucapkan terima kasih kepada Kementerian Riset dan Pendidikan Tinggi dan semua pihak yang telah membantu penelitian ini.

\section{DAFTAR PUSTAKA}

[1] Gunawan, G. 2017. Keterampilan Berpikir Dalam Pembelajaran Sains. Mataram: Arga Puji Press.

[2] Kivunja, C. 2015. Exploring The Pedagogical Meaninag and Implications of The 4Cs "Super Skills" For The 21st Century Through Bruner's 5E Lenses of Knowledge Construction to Improve Pedagogies of The New Learning Paradigm. Creative Education, 6(02):224239.

[3] Gagne, R. M. 1980. Is educational technology in phase? Educational Technology, 20(2):7-14.

[4] Gunawan, G., Harjono, A., \& Sutrio, S. 2015. Multimedia Interaktif dalam 
Pembelajaran Konsep Listrik bagi Calon Guru. Jurnal Pendidikan Fisika dan Teknologi. 1 (1): 9-14.

[5] Gunawan, G. 2015. Model Pembelajaran Sains Berbasis ICT. Mataram: FKIP UNRAM.

[6] Taasoobshirazi, G., \& Farley, J. 2013. A Multivariate Model of Physics Problem Solving. Learning and Individual Differences, 24: 53-62.

[7] OECD. 2014. PISA 2012 Results in Focus: What 15-years-olds know and what they can do with what they know.

[8] Heller, P., Keith, R., \& Anderson, S. 1992. Teaching problem solving through cooperative grouping. Part 1: Group versus individual problem solving. American journal of physics, 60(7): 627-636.

[9] Susiana, N., Yuliati, L., \& Latifah, E. 2017. Analisis Pembelajaran Berdasarkan Profil Kemampuan Pemecahan Masalah Fisika Siswa Kelas X SMA. Prosiding Seminar Nasional III Tahun 2017, 210-214.

[10] Saputra, M. D., Joyoatmojo, S., Wardani, D. K., \& Sangka, K. B. 2019. Developing Critical-Thinking Skills through the Collaboration of Jigsaw Model with Problem-Based Learning Model. Internasional Journal of Instruction, 1291): 1077-1094.

[11] Huda, N., Hikmawati, H., \& Kosim, K. (2019). Pengaruh Pendekatan Kontekstual Berbantuan Alat Peraga Terhadap Penguasaan Konsep dan Kemampuan Pemecahan Masalah Fisika. Jurnal Pijar Mipa, 14(1), 62-72.

[12] Pedaste, M., Mäeots, M., Siiman, L. A., De Jong, T., Van Riesen, S. A., Kamp, E. T., \& Tsourlidaki, E. 2015. Phases of InquiryBased Learning: Definitions and The Inquiry Cycle. Educational research review, 14, 47-61.

[13] Primadani, R., Tukiran, T., \& Jatmiko, B. 2017. Pengembangan Perangkat Pembelajaran Fisika Model Structured Inquiry Untuk Meningkatkan Keterampilan Pemecahan Masalah Siswa Pada Materi Fluida Statis. JPPS: Jurnal Penelitian Pendidikan Sains, 6(1):1235-1245.

[14] Prahani, B.K,. Limatahu, I,. Soegimin,. Yuanita, L., \& Nur, M. 2016. Effectiveness of Physics Learning Material Through Guided Inquiry Model to Improve Student's Problem Solving Skills Based on Multiple Representation. International Journal of Education and Research: 231-242.
[15] Ausubel, D. P. 1960. Educational Psycology: A Cognitive View. New York: Holt, Rinehart and Winston.

[16] Ni, L. B,. Syahada, N,. \& Hasni. 2016. Advance Organizer: Cognitive Instructional Strategy. International Journal of Computer Networks and Wireless Communications (IJCNWC): 53-57.

[17] Joyce, B., Weil, M.., \& Alhoun, E. 2013. Model of Teaching. Chicago: University of Chicago Press.

[18] Mayer, R. 2008. Learning and Instruction. New Jersey: Pearson Education, Inc.

[19] Thacker, E., \& Friedman, A. 2017. Social Studies Teachers' Design and Use of Inquiry Modules. Contemporary Issues in Technology and Teacher Education, 17(3), 360-387.

[20] Harjono, A., Gunada, I. W., Sutrio. S., \& Hikmawati, H. 2018. Penerapan Advance organizer dengan Model Pembelajaran Ekspositori Berpola Lesson Study Untuk Meningkatkan Hasil Belajar Fisika Peserta Didik. Jurnal Pendidikan Fisika dan Teknologi, 4(1): 141-150.

[21] Amanah, P. D., Harjono, A., \& Gunada, I. W. 2017. Kemampuan Pemecahan Masalah Dalam Fisika Dengan Pembelajaran Generatif Berbantuan Scaffholding dan Advance Organizer. Jurnal Pendidikan Fisika dan Teknologi, 3(1): 84-91.

[22] Hamdanillah, N., Harjono, A., \& Susilawati, S. 2017. Pengaruh Model Pembelajaran Advance Organizer Menggunakan Video Pembelajaran Terhadap Hasil Belajar Fisika Peserta Didik. Jurnal Pendidikan Fisika dan Teknologi, 3(2): 119-127.

[23] Thiagarajan, S., Semmel, D. S., \& Semmel, M. I. 1974. Instructional Development for Training Teacher of Exceptional Children. Bloomington Indiana: Indiana University.

[24] Ratumanan, G.T., \& Laurens, T. 2011. Evaluasi Hasil Belajar Tingkat Satuan Pendidikan. Surabaya: UNESA University Press.

[25] Trisnawati, A. A. I. A., Jufri, A. W., \& Ramdani, A. (2017). Pengembangan Model Praktikum Berbasis Software Most Probable Number (Mp-Bsmpn) Pada Mata Kuliah Mikrobiologi Air. Jurnal Pijar Mipa, 12(2), 44-50.

[26] Ramadhani, R. 2016. Pengembangan Perangkat Pembelajaran Matematika yang Berorientasi pada Model Problem Based Learning. Jurnal matematika Kreatif Inovatif, 7(2): 116-122. 